\title{
Mixing Experimental Study on Water-rock Interaction (WRI) in the Inland Shallow Salt Groundwater Area
}

\author{
Li Changsuo $^{1}$, Xing Liting ${ }^{*}, 2$, Wang Liyan ${ }^{3}$, Zhang Fengjuan ${ }^{2}$ and Liu Bo ${ }^{3}$ \\ ${ }^{1}$ Shandong Provincial Geo-mineral Engineering Exploration Institute, Jinan, 250014, China \\ ${ }^{2}$ College of resources and environment, University of Jinan, Jinan, 250022, China \\ ${ }^{3}$ Shandong Zhengyuan Construction Engineering Co.Ltd, Jinan 250100, China
}

\begin{abstract}
The shallow salt groundwater is widely distributed in North Shandong, which makes it difficult for people and livestock to drink daily. In addtion, the genetic mechanism of shallow salt groundwater is complicated. The study was carried out in Xiyan Village of Jiyang County, it choosed the silt buried in 3-9 m depth, shallow salt groundwater and atmospheric precipitation as test materials to measure chemical composition of groundwater. Base on soluble salt test, rain-saltwater mixing test and rain-saltwater-silt mixing test, ions component of mixture were measured, the hydrogeochemical action process of WRI was analyzed and formation-evolution of inland saltwater was deepened knowledge. It is shown that (1) The occurrence threshold of WRI was 20\%, which was the volume of saltwater in mixture. (2) When the rainwater, saltwater and silt were mixed together for 12 hours, calcite and dolomite precipitated, halite and gypsum were in dissolved state. When the volume of saltwater in mixture was larger than $20 \%$, gypsum was closed to saturation, the main cation exchange was $\mathrm{Mg}-\mathrm{Na}$, the exchange of $\mathrm{Ca}-\mathrm{Na}$ was in the second place; The order for anion adsorption amount of aquifer medium was $\mathrm{SO}_{4}{ }^{2-}>\mathrm{HCO}_{3}{ }^{-}>\mathrm{Cl}^{-}$. The study proves that groundwater circulation is slow and continual, some hydrochemical actions (i.e. ion exchange, adsorption, mineral dissolution or precipitation, and strong evaporation-concentration) are happened during the evolution process of inland shallow groundwater. All these will lead to $\mathrm{Cl} \bullet \mathrm{SO} 4-\mathrm{Mg} \bullet \mathrm{Na}$ type salt or slight salt water with TDS being larger than $2 \mathrm{~g} \cdot \mathrm{L}^{-1}$.
\end{abstract}

Keywords: Shallow salt groundwater, ion exchange, adsorption, mineral dissolution/precipitation.

\section{INTRODUCTION}

Effected by water-rock interaction, Evaporationconcentration and human activity etc., the evolution of the inland salt groundwater quality goes through a process of salinization slowly and continually [1-5]. Studies have confirmed that formation of brackish water were main relation to low-lying terrain, small precipitation, strong evaporation, and high salt content of aquifer medium in Ningnan area [6]. The high mineralized groundwater was formed with a process of $\mathrm{Na}-\mathrm{Ca}$ exchange and accumulation of solutes in south-western Sicily, Italy [7].

Compared with the coastal seawater intrusion region, the hydrochemical type is more complex in inland salt water area, the predominant ions are $\mathrm{Cl}^{-}, \mathrm{SO}_{4}{ }^{2-}, \mathrm{Na}^{+}$and $\mathrm{Mg}^{2+}$, and the clay content of aquifer medium in saltwater zone is high $[8,9]$. Such as North Shandong Plain, it located at the north of Yellow River, salt groundwater caused by continental salinization is distributed throughout the whole area [10]. The diversity between water and lithology causes that the geochemical characteristics is different between salt water zone and coastal salt region. Therefore, the water and soil

*Address correspondence to this author at the College of resources and environment, University of Jinan, 250022, Jinan, China; Tel: 13853101263; E-mail: xlting596@163.com samples were collected from Xiyan Village of Jiyang County as test materials. The hydrochemical actions were analyzed in the process of water-rock interaction through rainsaltwater-silt mixing test. And the hydrogeochemical process research of inland salt groundwater region has important implications for clearing the formation and evolution mechanism of continent salt groundwater.

\section{METHODS}

\subsection{Material Selection and Tested Material Collection}

The water samples were collected Xiyan Villiage of Jiyang County. The hydrochemistry type of the area was $\mathrm{Cl} \cdot \mathrm{SO}_{4}-\mathrm{Mg} \cdot \mathrm{Na}$, and the TDS was high (Table 1).

Table 1. Groundwater TDS in the study area.

\begin{tabular}{|c|c|c|c|c|c|c|}
\hline $\begin{array}{c}\text { Buried depth } \\
\text { /m }\end{array}$ & $\mathbf{9}$ & $\mathbf{8}$ & $\mathbf{7}$ & $\mathbf{6}$ & $\mathbf{5}$ & $\mathbf{4}$ \\
\hline \hline $\mathrm{TDS} / \mathrm{gL}^{-1}$ & 12.01 & 12.20 & 11.30 & 11.76 & 12.20 & 11.14 \\
\hline
\end{tabular}

Country as test materials. The hydrochemical actions were analyzed in the process of water-rock interaction through rain-saltwater-silt mixing test. And the hydrogeochemical process research of inland salt groundwater region 
has important implications for clearing the formation and evolution mechanism of continent salt groundwater.

Silt got by drilling core in the depth of 5-6 m was as WIR test material. The particle size of soil sample in 0.075 $0.005 \mathrm{~mm}$ occupys $86.7 \%$ of the total amount, the size less than $0.005 \mathrm{~mm}$ occupys $13.3 \%$, and the non-uniform coefficient of the sample is 8.48 . The result of X-ray diffraction analyses indicated that quartz occupys $55 \%$, feldspar occupys $15 \%$, kaolinite occupys $10 \%$, illite occupies $8 \%$, montmorillonite occupies $12 \%$. It collected the undisturbed soil shallower than exploration depth in $44 \mathrm{~m}$ to do soluble salt test.

Compared with the content of clay mineral in coastal seawater intrusion area, the content is the highest in Xiyan Village. The content of expansive clay mineral (montmorillonite) and non-expansive clay mineral (kaolinite) in Xiyan Village was far higher than the content in Maojiazhuang area of the lower Dagu River, Luohandong Formation of Ordos Basin took second place $[11,12]$ (Table 2).

The water samples were collected the shallow salt groundwater and precipitation of Xiyan Village, the chemical analyses of the samples could be seen in Table 3 . The water samples were stored with sealing and were filtered by 0.45 um microporous membrane before testing. It used Grade 3 distilled water for test, which was measured up to standard of GB6682-92.

\subsection{Water-Rock Interaction Experiment Experiment Design}

- Taking the soil samples for air drying, impurity removal, grinding, sieving (diameter in $0.315-0.08 \mathrm{~mm}$ ) and drying $\left(105 \mathrm{C}^{\circ}, 4 \mathrm{~h}\right) .7$ equal samples were put into $50 \mathrm{ml}$ centrifuge tubes respectively, adding $50 \%$ alcohol along the centrifuge tube wall, stirring efficiently, centrifugal (100 r.min $\left.{ }^{-1}\right)$, dislodging the supernatant, repeating 3 times.

- Filtering the salt water and rain water by $0.45 \mathrm{um}$ microporous membrane. Mixing saltwater and rain water in different proportion (the proportions of saltwater are $0 \%, 10 \%, 20 \%, 30 \%, 40 \%, 50 \%, 60 \%$, $70 \%, 80 \%, 90 \%$ and $100 \%)$.
- Mixing the rain-salt water mixture and soil samples for test together in the ratio of 2.5:1, oscillating the sealed water-rock mixture by water bath of constant temperature $\left(17^{\circ} \mathrm{C}, 100 \mathrm{rmin}^{-1}\right)$ for 12 hours, determining the index after oscillating [13].

\section{RESULT AND DISCUSSION}

\subsection{Hydrogeochemical Actions During the Process of Water-Rock Interaction}

Results showed that the specific conductivity increased amplitude of water-rock mixture was lower than the simply saltwater-rain mixture, when the different ratio mixture of saltwater and rain water interacted with aquifer medium after 12 hours. It is illustrated in Fig. (1). It is speculated that WRI should happen when proportion of salt water was $20 \%$, which was the critical mixing ratio.

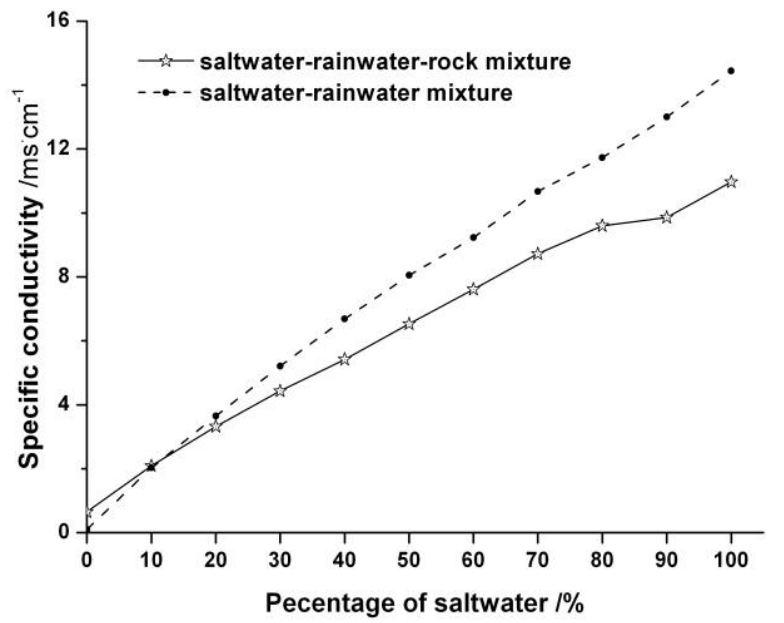

Fig.(1). Comparison curve of specific conductivity of salt-rain water mixture and water-rock mixture.

\subsection{Dissolution-Precipitation of Minerals During the Process of Water-Rock Interaction}

The saturation indexes of calcite, gypsum, halite and dolomite were calculated from ion component of initial saltwater-rain mixture, later stage of salt-rain water mixture after 12 hours and later stage of water-rock mixture after 12 hours by PHREEQC. It is illustrated in Fig. (2).

Table 2. Statistic of typical mineral component $/ \%$.

\begin{tabular}{|c|c|c|c|}
\hline Sampling Site & Kaolinite & Illite & Montmorillonite \\
\hline \hline Maojiazhuang of the Lower Dagu River & 0.53 & 1.69 & 0.17 \\
\hline Xiyan Village of Jiyang & 10 & 8 & 12 \\
\hline Luohandong Formation of the Ordos Basin & 2 & 4 & $/$ \\
\hline
\end{tabular}

Table 3. Chemical analyses of water samples.

\begin{tabular}{|c|c|c|c|c|c|c|c|}
\hline Test Index & $\mathbf{N a}^{+}$ & $\mathbf{K}^{+}$ & $\mathbf{C a}^{2+}$ & $\mathbf{M g}^{2+}$ & $\mathbf{S O}_{\mathbf{4}}{ }^{2-}$ & $\mathbf{H C O}_{\mathbf{3}}{ }^{-}$ & $\mathbf{C l}^{-}$ \\
\hline \hline Tested saltwater & 1642 & 1.67 & 980 & 1028 & 2830 & 835 \\
\hline Tested rainwater & 46.67 & 0.11 & 10.2 & 35.76 & 109.82 & 9.85 & 3.1 \\
\hline
\end{tabular}


It can be seen from Fig. (2). that the saturation indexes of halite and gypsum were all below zero whether derived from simply salt-rain water mixing or WRI, and the dissolution of halite and gypsum contributed to content increasing of $\mathrm{SO}_{4}{ }^{2-}$, $\mathrm{Cl}^{-}, \mathrm{Ca}^{2+}$ and $\mathrm{Na}^{+}$in solution.

When the proportion of salt water increased from $0 \%$ to $20 \%$, after water-rock mixing 12 hours, saturation index of calcite increased from (-2.23 -0.84) to (0.09 0.22). And the changing trend of saturation index of dolomite was analogous, namely with the increase of salt water proportion, calcite and dolomite changed from dissolution state to precipitation state. When the salt water proportion was greater than or equal to $20 \%$, gypsum was approached saturation, of which the saturation index was greater than 0.5 , the calcite and dolomite were in supersaturating state. Precipitation of calcite and dolomite was conducive to reduce the contents of $\mathrm{Mg}^{2+}, \mathrm{Ca}^{2+}$ and $\mathrm{HCO}_{3}{ }^{-}$.

The typical mineral saturation indexes of salt-rain water mixture revealed small changes after 12 hours, which showed that the mixing of saltwater and rainwater was not a simple mechanical mixing process, complexation maybe occurred. After water-rock mixing 12 hours, dolomite and calcite precipitated, gypsum and halite were in a dissolved state.

\subsection{Difference in Laws of Ion Exchange and Adsorption in the Process of Water-Rock Interaction}

As shown in Fig. (3), the difference distribution map of the ion components in the two mixtures was drawn according to the changing of ion components in the two mixtures after 12 hours.
It is showed that when the saltwater proportion was below 20\%, the ion component content of rain-saltwater mixture was less than which in water-rock mixture. When it was greater than or equal to $20 \%$, the contents of $\mathrm{Ca}^{2+}$, $\mathrm{HCO}_{3}{ }^{-}, \mathrm{SO}_{4}{ }^{2-}, \mathrm{Cl}^{-}$and $\mathrm{Mg}^{2+}$ in saltwater-rain mixture were more than that in water-rock mixture, but the content of $\mathrm{Na}^{+}$ was opposite. It meant that the hydrogeochemical action during the saltwater and rainwater mixing process in inland saltwater area couldn't be ignored.

\section{- Anion adsorption during water-rock interaction}

When the saltwater proportion was greater than or equal to $20 \%$, through the saturation index of gypsum was greater than -0.5 and approached saturation, the content of $\mathrm{SO}_{4}{ }^{2-}$ in the mixture was decreased greatly. It is illustrated in Fig. (3), from which it could be concluded that the $\mathrm{SO}_{4}{ }^{2-}$ adsorbing capacity of the medium was maximum. And then it showed that when the aquifer medium was saturated by the rain in nature, clay mineral surface adsorbed a large amount of $\mathrm{HCO}_{3}^{-}$at the first time, and then when the saltwater permeated and $\mathrm{SO}_{4}{ }^{2-}-\mathrm{HCO}_{3}{ }^{-}$exchange process occurred, which caused $\mathrm{SO}_{4}{ }^{2-}$, was adsorbed meanwhile $\mathrm{HCO}_{3}{ }^{-}$was desorbed, and the adsorbing capacity of $\mathrm{HCO}_{3}{ }^{-}$was reduced. Therefore, because of the competitive adsorption and anion reversible exchange, after WRI, the order of anion adsorption content was $\mathrm{SO}_{4}{ }^{2-}>\mathrm{HCO}_{3}{ }^{-}>\mathrm{Cl}^{-}$. It is shown the adsorption capacity of aquifer medium for $\mathrm{Cl}^{-}$was lesser. When the saltwater proportion was over $20 \%$, it could be inferred that the capacity of aquifer medium adsorption was larger than the halite solution, and capacity of adsorbing $\mathrm{SO}_{4}{ }^{2-}$ was the biggest but $\mathrm{Cl}^{-}$was the smallest, which caused the content reduction of $\mathrm{SO}_{4}{ }^{2-}$ and $\mathrm{Ca}^{2+}$.

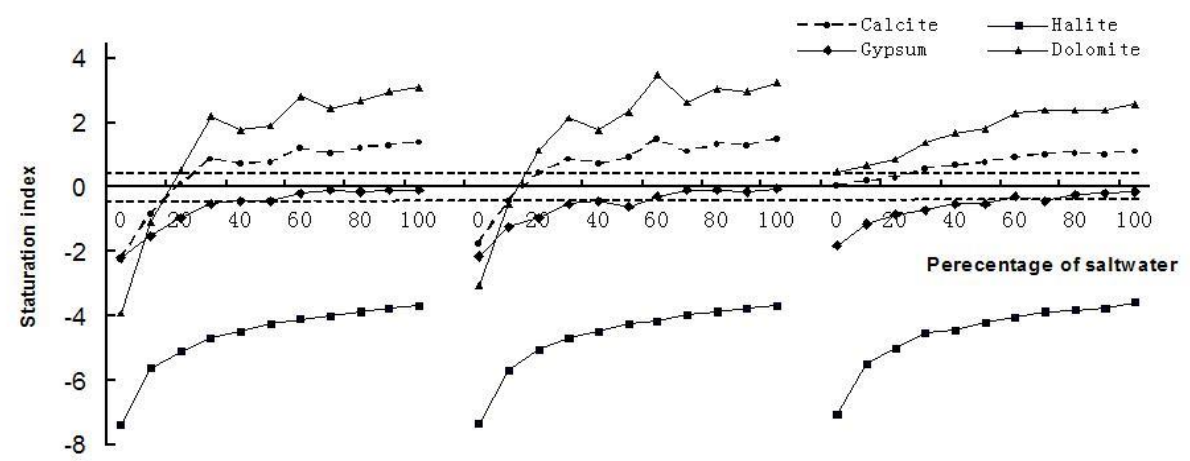

Fig.(2). Changing curve of minerals saturation indexes for salt-rain mixture and water-rock mixture.

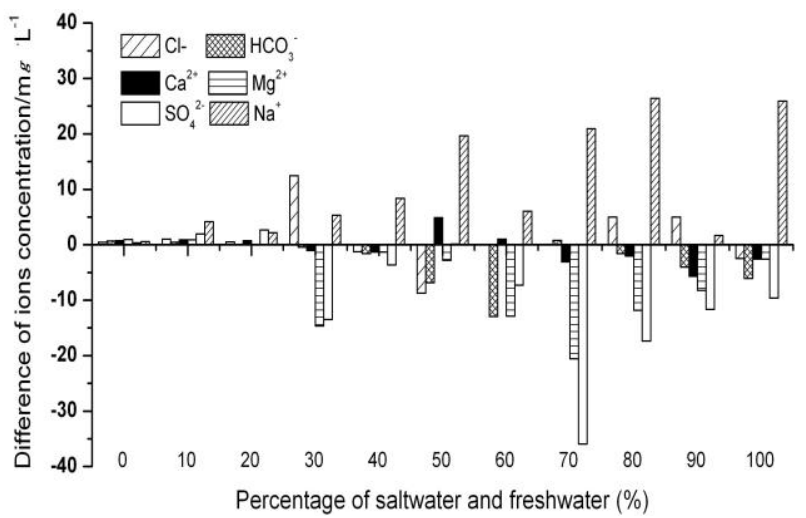

Fig. (3). Variation tendency of ions content in the later stage of water-rock interaction and rain-saltwater mixture. 
- Cation exchange during water-rock interaction

When the saltwater proportion was below 20\%, the content of cation in water-rock interaction mixture was increasing. The increased order was $\mathrm{Na}^{+}>\mathrm{Mg}^{2+}>\mathrm{Ca}^{2+}$. Compared with rain-saltwater mixture, when the saltwater proportion was greater than or equal to $20 \%$, the content decreasing amplitude of $\mathrm{Mg}^{2+}$ was bigger than $\mathrm{Ca}^{2+}$, while the content of $\mathrm{Na}^{+}$showed an increasing trend. It could be inferred that $\mathrm{Mg}^{2+}$ had an adsorption advantage during the water-rock interaction, a large amount of exchangeable $\mathrm{Na}^{+}$ was desorbed, and the main cation exchange was $\mathrm{Mg}-\mathrm{Na}$, $\mathrm{Ca}-\mathrm{Na}$ took the second place. $\mathrm{Mg} / \mathrm{Ca}-\mathrm{Na}$ cation exchange was happened.

In addition, for the shallow silt aquifer in plain area, the content of $\mathrm{Na}^{+}$showed an increased tendency in mixture with different saltwater proportion, it may had a certain relationship with incongruent hydrolytic action of albite in acidic conditions. The reaction equation is shown as following (1):

$$
\begin{aligned}
& 2 \mathrm{Na}\left[\mathrm{AlSi}_{3} \mathrm{O}_{8}\right]+2 \mathrm{H}_{2} \mathrm{CO}_{3}+\mathrm{H}_{2} \mathrm{O}=2 \mathrm{Na}^{+}+2 \mathrm{HCO}_{3}{ }^{-}+4 \mathrm{SiO}_{2}+ \\
& \mathrm{Al}_{2}\left[\mathrm{Si}_{2} \mathrm{O}_{5}\right][\mathrm{OH}]_{4}
\end{aligned}
$$

Therefore, in inland saltwater area, a series of hydrogeochemical reactions happened during the rainsaltwater alternating action process and it presented an increase tendency of $\mathrm{Na}^{+}$content. $\mathrm{Na}^{+}$was the main contribution factor in inland groundwater mineralization, and groundwater hydrochemical type was complicated in this area, which was $\mathrm{Cl} \cdot \mathrm{SO}_{4}-\mathrm{Mg} \cdot \mathrm{Na}$ type.

\section{CONCLUSION}

- The mixture experiment shows that mixing of saltwater and rain is not a simple mechanical mixing process. Laws of dissolution-precipitation of minerals and cation exchange-adsorption are different in the water-rock interaction with different saltwater-rain ratios. Gypsum and halite are in a dissolved state while dolomite and calcite precipitate. When the saltwater proportion is over $20 \%$, the main cation exchange is $\mathrm{Mg} / \mathrm{Ca}-\mathrm{Na}$, and $\mathrm{SO}_{4}{ }^{2-}$ adsorbing capacity of aquifer medium is the biggest while $\mathrm{Cl}$ - is relatively stable.

- Water-rock interaction experiment preliminarily confirmed that ion exchange, ion adsorption and dissolution-precipitation of minerals are existed in shallow groundwater circulation process, which causes the complicated groundwater hydrochemical types of the inland saltwater area. Within strong evaporation concentration, content of TDS, $\mathrm{Na}^{+}, \mathrm{Mg}^{2+}, \mathrm{Cl}^{-}, \mathrm{SO}_{4}{ }^{2-}$ are increased and slight salt water in $\mathrm{SO}_{4} \cdot \mathrm{Cl}-\mathrm{Mg} \cdot \mathrm{Na}$ type is formed.

\section{CONFLICT OF INTEREST}

The author confirms that this article content has no conflict of interest.

\section{ACKNOWLEDGEMENTS}

This paper is aided by the National Natural Science Foundation (41172222, 41472216), Science and Technology Development Plan Project of Jinan (201303082) and Graduate Innovation Fund Project of University of Jinan (YCXZ13004).

\section{REFERENCES}

[1] X. Q. Li, Q. S. Yu, X. W. Hou, and L. Zhang, "a study of the characteristics of groundwater circulation and theformation of bitter and saline groundwater in the qingshuihe basin in the southern ningxia", Journal of Hydrogeology and Engineering Geology, pp.46-51, 2006.

[2] Q. H. Zhang, Y. R. Zhang, Y. P. Zhao, and Z. Z. Ma, "Geochemical evolution of groundwater and hydro geochemical modeling in jinta basin", Journal of Arid Land Geography, vol.9, pp.772-776, 2011.

[3] Z. H. Zheng, D. H. Shi, Z. L. Shen, and Y. Q. Xue, "Evolution and development of groundwater environment in north china plain under human activities. acta geoscientia sinica” , Journal of Acta Geoscientia Sinica, vol.18, pp.337-344, 1997.

[4] Q. S. Zhao, J. Feng, and Y. S. An, "Deep groundwater water quality evolution in dezhou city", Journal of Scientia Geographica Sinica, vol.29, pp.766-771, 2009.

[5] S. Mehta, A. E. Fryar, R. M. Brady, and R. H. Morin, " Modeling regional salinization of the ogallala aquifer, southern high plains, tx, USA," Journal of Hydrology, vol.238, pp.44-64, 2000.

[6] C. G. Zhou, and X. Q. Bai, "The causes of brackish groundwater in southern ningxia", Journal of Coal Geology and Exploration, pp.36-38, 1999.

[7] G. Crescimanno, and A. D. Santis, "Bypass flow, salinization and sodication in a cracking clay soil", Journal of Geoderma, pp.307321, 2004.

[8] Q. Liu, "Study on Water-rock Interaction in Saltwater and Freshwater Transitional Zone", Journal of Ocean University of China, pp.71-73, 2008.

[9] X. H. Zhou, J. Zhou, X. L. Zheng, G. Q. Lin, and J. W. Wu, "Study on water sensitivity of the porous media at saline -freshwater interface," Journal of Marine Environmental Science, vol.26, pp.301-312, 2007.

[10] G. Q. Lin, "Mechanism and application of abrupt changes of hydraulic conductivity on the seawater-freshwater interface", $D$ Qingdao: Ocean University of China, pp.29-30, 2006.

[11] X. N. Zhou, S. Y. Liu, and Z. Wang, "The chemical characteristics and available analysis of shallow groundwater in the typical area of plain of north china - take hengshui in example", Journal of Water Sciences and Engineering Technology, pp.56-59, 2008.

[12] Y. Xie, J. Wang, L. X. Li, Z. W. Xie, G. Zheng, M. H. Li, and X. S. Jiang, "Distribution of the cretaceous clay minerals in ordos basin, china and its implication to sedimentary and diagenetic enviroment", Journal of Geological Bulletin of China, vol.29, pp.94-103, 2010.

[13] J. G. Ren, "Experimental study of chemical processes in a saline water-wreshwater transition zone", D. Qingdao: Ocean University of China, pp.83-90, 2007. 